\title{
Assessment of Hygiene Status and Environmental Conditions among Street Food Vendors in South-Delhi, India
}

\author{
Sneha Kumari ${ }^{1}$, Priyanka Sharma², Geeta Yadav³ , Umang Salodia ${ }^{4}$, \\ Lalit Chandrawanshi ${ }^{5}$, Jugal Kishore ${ }^{6}$
}

\begin{abstract}
Introduction: Rapid urbanization has led to increased need for informal sector services in India. Street food vendors are also among them. Their role is vital in maintenance of hygienic food conditions. But their hygienic status and environmental conditions are relatively sub-standard. So, an assessment at their level is required for formulation of guidelines.

Methods: A total of 130 vendors were included in the study by convenient sampling. Face-to-face interview technique with a questionnaire was used to gather data.

Results: Personal hygiene of the street food vendor is poor. Gloves (10.8\%) and aprons (3.8\%) were used by very less number of vendors. Besides these hazards, exposure to dust (80\%) and flies (71.5\%) was present.

Conclusion: Street food vendors are exposed to personal and environment hazards. Lack of any training on food hygiene and safety is a major setback. There is need to regulate these vendors with mandatory certification.
\end{abstract}

Keywords: Personal hygiene, Street food, Waste disposal

\section{Introduction}

On World Health Day 2015, food safety was recognized and declared as the theme of the year by World Health Organization (WHO). Five key elements of food safety which are clean, separate raw and cooked food, cook food thoroughly, keep food at safe temperatures, use safe water and raw materials were advocated by the WHO. ${ }^{1}$ These elements serve as practically applicable guide to all the persons involved in food handling, be it vendors, food sellers or any other food handler even at the household level. Food security is important as zero hunger is amongst one of the sustainable goals. But only ensuring food availability will not solve the purpose. The food should be safe and hygienic to serve its role. Food-borne illnesses globally cost an estimated 2 million lives annually, especially in the developing countries. ${ }^{1}$

Street food as defined by FAO includes wide range of ready-to-eat foods and beverages sold and sometimes prepared in public places, notably streets. ${ }^{2}$ The national policy for street vendors defines street vendor as any person who sells food in temporary establishments. ${ }^{3}$ So a street food vendor will be street vendor selling ready-to-eat foods and beverages.

${ }^{1}$ Senior Resident, ${ }^{2,4}$ Junior Resident (2nd Year), ${ }^{3}$ Professor, ${ }^{5}$ Junior Resident (Final Year), ${ }^{6}$ Director Professor \& Head, Department of Community Medicine, VMMC \& Safdarjung Hospital, New Delhi.

Correspondence: Dr. Priyanka Sharma, VMMC \& Safdarjung Hospital, New Delhi.

E-mail Id: sharma.priyankay@gmail.com

Orcid Id: http://orcid.org/0000-0003-1346-3453

How to cite this article: Kumari S, Sharma P, Yadav G et al. Assessment of Hygiene Status and Environmental Conditions among Street Food Vendors in South-Delhi, India. Epidem Int 2017; 2(3): 4-9.

Digital Object Identifier (DOI): https://doi.org/10.24321/2455.7048.201713

ISSN: $2455-7048$ 
FAO also stated that approximately 2.5 million people eat street food daily. ${ }^{4}$

In India, due to rapid urbanization and population explosion, the demand for informal service-oriented activities, including street food vending, has increased rapidly. Informal sector employs $25 \%$ people globally. ${ }^{5}$ In metropolitan cities of India, $2 \%$ of the population is constituted by street vendors. ${ }^{3}$ Food handlers play an important role in food safety. ${ }^{6}$

Traditional processing methods, poor personal hygiene of food handlers, improper use of additives, presence of pathogenic bacteria, and environmental contaminants are the main causes why street food can pose a major public health problem. Street food vendors have a very poor social and health profile; there is practically no system of their health examination and availability of health services when they fall sick. Street food vendors are also deprived of information education and communication services regarding personal and food hygiene. They are forced to sell food in unhygienic environment. Previous studies conducted in Delhi had shown poor hygienic and environmental conditions among food vendors. ${ }^{6}$

So, present study was conducted with the primary objective to assess the acquaintance of street food vendors with food safety and hygiene practices among them whose findings have been published elsewhere. ${ }^{7}$ We had secondary objectives to observe their hygiene status, health profile and nearby environmental conditions. The findings related to secondary objectives are presented in this article.

\section{Methods}

The methodological details have been provided in previously a published article. ${ }^{7}$ In brief, we did a cross-sectional study among 130 street food vendors of South Delhi in the year 2016. Sample size was arrived by taking prevalence of open wounds among street food vendors as $9 \%,{ }^{6}$ and absolute precision of $5 \%$. Convenient sampling technique was employed. Inclusion criterion was any vendor selling ready to eat food or drinks on a temporary static structure/ mobile stall or head load. Those serving food in a permanent establishment were excluded.

Written informed consent was taken from each participant. Face-to-face interview technique was used to collect the data with the help of a pre-designed, semi-structured, interviewer administered questionnaire. The questionnaire was made in English, translated into Hindi also to eliminate bias. Information about socio-demographic profile, awareness regarding food safety and hygiene and related practices was collected. An observational checklist to study the hygiene status, health profile and nearby environmental conditions was also used.

\section{Data Analyses}

All collected data was entered in MS Excel and analyzed by SPSS software version16.0. Univariate analysis was done using descriptive statistics. Simple tables (Tables 1, 2, and 3) were used for data representation.

\section{Ethical Consideration}

Written informed consent was taken from each participant and all information was kept confidential and used for study purpose only. Participants were informed about the purpose of the study and told that they were free to withdraw from the study at any point of time.

\section{Results}

Sociodemographic information has been provided in another article. Brief information is also provided here. 
Table 1.Sociodemographic Profile of the Study Participants $(\mathrm{N}=130)$

\begin{tabular}{|c|c|c|}
\hline S. No. & Variable & Percentage (Frequency) \\
\hline 1. & \multicolumn{2}{|c|}{ Sex Distribution } \\
\hline & Female & $11.5(15)$ \\
\hline & Male & $88.5(115)$ \\
\hline 2. & \multicolumn{2}{|c|}{ Marital Status } \\
\hline & Unmarried & $30(39)$ \\
\hline & Married & $70(91)$ \\
\hline 3. & \multicolumn{2}{|c|}{ Native Place } \\
\hline & Delhi & 14.6(19) \\
\hline & Bihar & $18.4(24)$ \\
\hline & Uttar Pradesh & $40.8(53)$ \\
\hline & Others* & $26.2(34)$ \\
\hline 4. & \multicolumn{2}{|c|}{ Age Groups (in completed years) } \\
\hline & $10-19$ & $6.2(8)$ \\
\hline & $20-29$ & $36.9(48)$ \\
\hline & $30-39$ & $40.8(53)$ \\
\hline & $40-49$ & $12.3(16)$ \\
\hline & 50 and above & $3.8(5)$ \\
\hline 5. & \multicolumn{2}{|c|}{ Educational Status } \\
\hline & Illiterate & $23.1(30)$ \\
\hline & Primary school & $26.9(35)$ \\
\hline & Middle school & $26.2(34)$ \\
\hline & Secondary school & $18.5(24)$ \\
\hline & Senior secondary school & $5.3(7)$ \\
\hline 6. & \multicolumn{2}{|c|}{ Structure Used for Vending } \\
\hline & Cart & $53.1(69)$ \\
\hline & Portable table & $20(26)$ \\
\hline & Table & $20(26)$ \\
\hline & Van & $3.1(4)$ \\
\hline & Cycle & $2.3(3)$ \\
\hline & Ground & $1.5(2)$ \\
\hline
\end{tabular}

*Others include Haryana, Himachal Pradesh, Rajasthan, Gujarat, Mizoram, Nepal and Bangladesh.

Out of 130 vendors, majority were males and in the age group of 30-39 years. Three-fourths were literate. Regarding marital status, 70\% (91) were married. Most of the vendors (85.5\%) originally belonged to states other than Delhi. Most common structure used for vending the food was cart, used by $53.1 \%$ (69) vendors, followed by portable tables which were used by $20 \%$ (26) vendors, simple tables by $20 \%(26)$, vans by $3.1 \%(4)$, bicycles by $2.3 \%$ (3) and on-ground, without using any structure, by only $1.5 \%(2)$.

Table 2.Observational Checklist for Nearby Environmental Conditions and Health Profile ( $\mathrm{N}=130)$

\begin{tabular}{|c|c|c|c|}
\hline S. No. & Variable & \multicolumn{2}{c|}{$\begin{array}{c}\text { Absent } \\
\text { Percentage (Frequency) }\end{array}$} \\
\cline { 1 - 2 } A. & Nearby Environment & $80(104)$ & $20(26)$ \\
\hline 1. & Dust & $86.2(112)$ & $13.8(18)$ \\
\hline 2. & Vehicular pollution & $65.4(85)$ & $34.6(45)$ \\
\hline 3. & Nearby garbage heaps & $17.7(23)$ & $82.3(107)$ \\
\hline 4. & Open drains & $71.5(93)$ & $28.5(37)$ \\
\hline 5. & Flies & $86.9(113)$ & $13.1(17)$ \\
\hline 6. & Waste bin for refuse disposal & Health Profile of Food Vendors \\
\hline B. & Cough & $6.2(8)$ & $86.2(112)$ \\
\hline 1. & Running nose & $1.5(2)$ & $93.8(112)$ \\
\hline 2. & Lice infestation in hair & $2.3(3)$ & $98.5(128)$ \\
\hline 3. & Conjunctivitis/discharge from eyes & & $97.7(127)$ \\
\hline 4. & &
\end{tabular}


While observing nearby environment, we found that majority of the vendors were having dust $(80 \%)$ and vehicular pollution (86.2\%) in the surrounding environment. Adding to this, there were nearby garbage heaps among $65.4 \%$ vendors. Flies were present and a source of menace among $71.5 \%$ vendors' environment. Majority of the vendors had kept dustbins for garbage disposal but rest of the vendors were throwing their garbage on roads. Out of 113 vendors who had dustbins, $74.7 \%$ had covered dustbins, which was a good practice.

About $14 \%$ of vendors were having cough while working and $6 \%$ had running nose and about $2 \%$ had conjunctivitis. Out of total 130 vendors, lice infestation in hair was seen in $2.31 \%$ of the subjects.

Table 3.Observational Checklist for Personal Hygiene Status of Vendors $(N=130)$

\begin{tabular}{|c|c|c|}
\hline S. No. & Variable & Percentage (Frequency) \\
\hline 1. & \multicolumn{2}{|c|}{ Hair } \\
\hline & Covered & $3.1(4)$ \\
\hline & Uncovered but clean & $88.5(115)$ \\
\hline & Uncovered and dirty & $8.4(11)$ \\
\hline 2. & \multicolumn{2}{|c|}{ Hands } \\
\hline & Wounds absent & $90(117)$ \\
\hline & Wounds present but covered & $3.8(5)$ \\
\hline & Uncovered wounds & $6.2(8)$ \\
\hline 3. & \multicolumn{2}{|c|}{ Hand Accessories } \\
\hline & Worn & $81.5(106)$ \\
\hline & Not worn & $18.5(24)$ \\
\hline 4. & \multicolumn{2}{|c|}{ Gloves } \\
\hline & Worn & $10.8(14)$ \\
\hline & Not worn & $89.2(116)$ \\
\hline 5. & \multicolumn{2}{|c|}{ Nails } \\
\hline & Clean and cut & $48.5(63)$ \\
\hline & Unkempt & $51.5(67)$ \\
\hline 6. & \multicolumn{2}{|c|}{ Hands Cleaned with } \\
\hline & Soap and water & $42.3(55)$ \\
\hline & Only water & $33.9(44)$ \\
\hline & Rubbed with dish towel & $22.3(29)$ \\
\hline & Sanitizer & $1.5(2)$ \\
\hline 7. & \multicolumn{2}{|c|}{ Clothes } \\
\hline & Clean & $70.8(92)$ \\
\hline & Dirty & $24.6(32)$ \\
\hline & Torn & $4.6(6)$ \\
\hline 8. & \multicolumn{2}{|c|}{ Aprons } \\
\hline & Worn & $3.8(5)$ \\
\hline & Not worn & $96.2(125)$ \\
\hline 9. & \multicolumn{2}{|c|}{ Feet } \\
\hline & Wearing slippers & $65.4(85)$ \\
\hline & Wearing shoes & $31.5(41)$ \\
\hline & Barefoot & $3.1(4)$ \\
\hline 10. & \multicolumn{2}{|c|}{ Food Served with } \\
\hline & Gloved hands & $10.8(14)$ \\
\hline & Bare hands & $52.3(68)$ \\
\hline & Fork/spoon & $30.8(40)$ \\
\hline & Cup/plate/ladle & $6.1(08)$ \\
\hline
\end{tabular}

Head and hair were covered by only 3.1\% (4) vendors. Rest of the vendors did not cover their hair and head while handling food. There was no wound in hands of $90 \%$ (117) vendors. In the rest $10 \%$ (13) vendors, wound was present and out of those 13 vendors, $8(61.5 \%)$ had open uncovered wounds while 5 (38.5\%) had covered wounds. Nails were long and unkempt in 51.5\% (67) vendors and clean and cut in $48.5 \%$ (63) vendors. Hand accessories were worn by $81.5 \%$ (106) vendors. Among those 106 vendors, most common accessory worn was a ring $(73.6 \%)$ followed by 
a wrist watch in $27.4 \%$ and bracelets by $26.4 \%$ vendors (multiple responses were present). Only $10.8 \%$ vendors were seen wearing gloves while handling food.

Less than half of the vendors were found to clean their hands with soap and water. About $22 \%$ vendors were using dish towel to clean their hands. More than half of the vendors (52.3\%) were serving food with bare hands.

Only $70.8 \%$ (92) vendors were found wearing clean clothes while $24.6 \%$ (32) vendors wore dirty clothes and $4.6 \%$ (6) wore torn clothes at the time of observation. Only $3.8 \%$ (5) vendors were wearing aprons. $65.4 \%(85)$ had slippers in their feet, $31.5 \%$ (41) had shoes and 3.1\% (4) were barefoot.

\section{Discussion}

As all the vendors were selling food in temporary establishments, the nearby environmental conditions were sub-standard in case of almost all the vendors. The lack of any regulation on environmental conditions mandatory for these informal workers worsens the condition. This was similar to the finding of another study conducted in India, ${ }^{8}$ while, in a study conducted in Nigeria it was revealed that almost all vendors were having clean vending environment. ${ }^{8}$

We observed in $80 \%$ of the places dust was present and in $71.5 \%$ of the places flies were present which were higher than in previous studies. ${ }^{6,9,10}$ Vehicular pollution was present nearby among $86.2 \%$ vendors and this was much higher than found in other studies conducted in India. $6,10,11$ This shows that majority of the street food vendors were present alongside roads, thereby exposing food to toxic gases produced from vehicular fuel combustion.

Presence of nearby garbage heaps in our study (65.38\%) was comparable with other studies also, ${ }^{4}$ but it was higher as compared to previous studies conducted in Delhi and other parts of the world. ${ }^{6,9,11}$ This deteriorates the quality of food. Presence of flies adds to this problem by transmitting various food-borne infections. Open drains are potentially hazardous and could lead to injuries and accidents, which were present among $17.7 \%$ vendors. This was much higher compared to another study. ${ }^{6,11}$ They also serve as home to rodents. All this could aggravate the risk of transmission of various infections to the vendors and through food to the consumers also. About $13.1 \%$ vendors were throwing their garbage on road, which was comparable to the findings of other studies conducted in India and globally. ${ }^{8,11,12}$ But this was lower as compared to a study by Bhasin et al. in East Delhi. ${ }^{6}$ This difference could be possible due to different localities of the studies.

Cough, running nose and conjunctivitis were the common illnesses observed among food vendors lower than that found in another study. All these illnesses are infectious and could spread through fingers, fomites and flies, if not through food among the vendors and to the consumers. Lice infestation was present among lower percentage of vendors compared to previous studies. ${ }^{6}$

No head cover and apron was present in 99\% and 96\% of vendors respectively which was comparable with findings of studies conducted in India and other parts of the world..$^{8,11,13,14}$ This might not lead to food-borne illnesses, but affects consumers' trust. This is much higher as compared to studies conducted in other parts of world highlighting better hygienic practices among them. ${ }^{9,12} \mathrm{~A}$ higher proportion of vendors (70.8\%) was observed wearing clean clothes as compared to previous studies. ${ }^{4,6,15}$ But it was comparable to a study conducted in Ahmedabad. ${ }^{10}$

Almost $6 \%$ vendors were having uncovered wounds, similar to other studies. ${ }^{6,11}$ This was lower compared to studies conducted globally. ${ }^{9}$ Uncovered wounds may harbor fly infestation and transmission of infection. Vendors should be made aware about possible hazards of open wounds in food handling. Hand accessories were worn by majority of the vendors. This is much higher as compared to previous study. ${ }^{9,14}$ But it was similar to another study conducted in Assam and Hyderabad. ${ }^{8,15}$ These accessories could have microbiological contamination. Food handling without hand accessories and with mandatory gloves should be practiced by vendors. Less than half of the vendors were using soap for hand-washing, comparable to previous study..$^{10}$

Clean-cut nails found out in our study was in $48.5 \%$ vendors, much higher than a similar study in Delhi but lower than in other previous studies..$^{4,6,9,11-15}$ Yet more than half of the vendors were having dirty unkempt nails. This makes them prone to food-borne illnesses as well as soil-borne helminthic infections. The risk of transmission of such infections is also increased through food handling, if proper hygienic practices are not employed. Bacteriological examination of nail clippings of vendors have been found to harbor many pathogenic microbes. ${ }^{6}$

About one-thirds of the vendors were barefoot. This practice is hazardous as it could lead to injuries. Also, they are exposed to hookworm infestation as the worm enters the body through skin penetration. Food was served with bare hands by $52.3 \%$ vendors which was higher than in other studies. ${ }^{12,15}$ But it was lower than in the study conducted by Gawande et al. ${ }^{10}$

A small sample size along with lack of microbiological analysis of food and nail clippings and stool samples of vendors were major limitations of the study.

\section{Conclusion}

Street food vendors have a number of health problems and they are exposed to environmental pollution. There is no examination carried out by any agency. Similarly, training 
for personal and food hygiene is also non-existent. There is need to regulate these vendors with mandatory certification and regular training to ensure proper hygienic practices. Regular health examination should be done among informal sector employees also as they are usually devoid of many services to which formal sector employees are entitled.

\section{Conflict of Interest: None}

\section{References}

1. World Health Day 2015: Food safety. WHO global health days. WHO. Available from http://www.who. int/campaigns/world-health-day/2015/event/en/ [Last accessed on Mar 14, 2016].

2. Winamo FG, Allain A. Street food in developing countries: Lessons from Asia. FAO corporate document repository. Agriculture \& consumer protection. Available from: http://www.fao.org/docrep/u3550t/ u3550t08.htm [Last accessed on Mar 14, 2016].

3. Bhowmik SK. Street vendors in Asia: A review. Economical and Political Weekly 2005 May 28-Jun 10; 40(22/23): 2256-64.

4. Gadi C, Bala KL, Kumar A. Study of hygienic practices of street food vendors in Allahabad city, India and determination of critical control points for safe street food. The Allahabad Farmer Jan 2013 LXVIII(2): 1-10.

5. Sekar HR. Vulnerabilities and insecurities of informal sector workers: A study of street vendors. V V Giri National Labour Institute, Noida. Available from: http:// www.vvgnli.org/sites/default/files/publication_files/ Vulnerabilities\%20and\%20Insecurities\%20of\%20 Informal\%20Sector\%20Workers\%20A\%20Study\%20 of\%20Street\%20Vendors.pdf. [Last accessed on Mar 14, 2016].

6. Bhasin SK, Grover S, Sharma R et al. Hygiene status and food handling practices among street food vendors in East Delhi: An observational study. J Commun Dis 2009; 41(4): 229-37.

7. Sharma P, Kumari S, Panesar S et al. Food hygiene perceptions and safety practices among street food vendors in South Delhi: A cross-sectional study. International Journal of Scientific Research 2017 Jul; 6(7): 589-92.

8. Pokhrel P, Sharma D. A study on assessment of food safety knowledge and practices among the street food vendor of urban and semi urban areas of Guwahati, Assam. Int J Home Sci 2016; 2(2): 85-89.

9. Okojie PW, Isah EC. Sanitary conditions of food vending sites and food handling practices of street food vendors in Benin City, Nigeria: Implication for food hygiene and safety. J Environmental Public Health 2014; 2014: 1-6.

10. Gawande HA, Mishra AA, Shukla RN et al. Socioeconomic profile of street food vendors and quality evaluation of samosa and panipuri in Allahabad City, (UP) India. Int J Agriculture and Food Science Technology 2013; 4(3): 275-80.

11. Thakur CP, Mehra R, Narula $C$ et al. Food safety and hygiene practices among street food vendors in Delhi, India. Int J Current Research 2013 Nov; 5(11): 3531-34.

12. Eliku T. Hygienic and sanitary practices of street food vendors in the city of Addis Ababa, Ethiopia. Food Science and Quality Management 2016; 50: 32-38.

13. Monneyl, Agyei D, Owusu W. Hygienic practices among food vendors in educational institutions in Ghana: The case of Konongo. Foods 2013; 2: 282-94.

14. Bormann F, Adzinyo O, Letsa L. Safety and hygiene status of street vended foods in Ho, Ghana. Journal of Hospitality Management and Tourism 2016 Feb; 7(2): 25-32.

15. Reddi SG, Kumar RN, Balakrishna N et al. Microbiological quality of street vended fruit juices in Hyderabad, India and their association between food safety knowledge and practices of fruit juice vendors. International Journal of Current Microbiology and Applied Sciences 2015; 4(1): 970-82.

Date of Submission: 2017-08-11 Date of Acceptance: 2017-09-13 